\title{
Optimization of filament winding parameters for the design of a composite pipe
}

\author{
Chiara Colombo*, Laura Vergani \\ Politecnico di Milano, Department of Mechanical Engineering, Via La Masa 1, 20156 Milano, Italy
}

In the oil\&gas field, common steel pipelines experience well-known problems of corrosion and maintenance. The design with composite materials could avoid these problems and provide lightness to the overall structures. Standards and regulations guide the designer through the qualification steps, but they are constantly under review based on the increasing knowledge of the long term mechanical behaviour of these materials.

The aim of this work is to provide the designer with an analytical tool for the optimal design of a composite plain pipe, i.e. minimizing the wall thickness. The paper presents considerations useful in the design stage for the selection of the optimal fiber, matrix, volume fraction $V_{f}$, and winding angle $\theta$. The study simulates tests with inner pressure and axial loads, in accordance with the main applicable standards. Based on the analytical es-timations, we found a locus of optimal technological parameters with volume fraction $40 \%<V_{f}<60 \%$ and winding angle \pm $44.5^{\circ}<\theta< \pm 52.5^{\circ}$. From these considerations, we can suggest a customization in the pipe production, based on the estimated axial loads in exercise.

\section{Keywords:}

Glass fibre, Analytical modelling, Filament winding

\section{Introduction}

Industrial applications of pipes in composite materials are being more and more accepted due not only to their properties, but also to greater experience on the material behaviour. The main feature of fibre reinforced polymer (FRP) pipes is their resistance to corrosion, which results into a decrease of maintenance and life cycle costs with respect to the more classical steel pipes. This, together with their high strengthto-weight ratio and lightness, makes composite pipes very promising for different applications.

Examples can be found in the civil engineering above and below ground, i.e. low-pressure sewage, service and potable waters [1]. For instance, Jin et al. [2] presented an analytical study on strength and deflections of a buried glass-reinforced pipe. Other examples, but mainly dealing with vessels rather than pipes, are in the aerospace and automotive fields.

Focussing on the oil\&gas industry, the development of commercial FRP pipes began around 1960s and rapidly increased for onshore and off-shore oil and natural gas transportation, from well's head to households and commercial users, at higher pressures with respect to civil applications ([3] [4], [5] [6]).

Nowadays, especially in the last years, many studies became available from the scientific literature, describing the results of experimental tests on different composite materials. Focussing on glass reinforced polymers (GRP), Fig. 1 summarizes the state of the art for the design of pipes in terms of the pressure-diameter curve. The limiting curve is a hyperbola, setting constant the product $D \cdot p=3000$ [7]. Most of the current available products lay highly below this curve. This plot also gives some suggestions according to [8] for the manufacturing of pipes and pipe joints. However, the plot of Fig. 1 gives only a general overview of the manufacturing capacity and commercial availability of composite pipes; probably, many other pipes have been already designed and tested, but limited to the industries' know-how or even under patent.

Results of this investigation indicate there are a number or barriers that need to be overcome to make large diameter composite pipe a viable alternative for high-pressure natural gas transportation in the future. These barriers are mainly due to economic and technological problems [9], and can concern loadings, environmental conditions, material long term behaviour, external damages from transportation and during/post installation, joining and valving, automated quality control systems, quality controls and inspections, regulatory acceptance, etc.

The typical structure of a composite pipe consists of 3 layers (Fig. 2): 1) an inner thermosetting liner providing smoothness and low friction, and acting as a chemical barrier against hydrocarbon permeation; 2) several reinforcing layers made from fibre-reinforced thermosetting composites; 3 ) an outer cover (or jacket) protecting from the external

Received 8 January 2018;

Received in revised form 29 March 2018;

Accepted 27 April 2018

Available online 30 April 2018

\footnotetext{
* Corresponding author.

E-mail addresses: chiara.colombo@polimi.it, laura.vergani@polimi.it (L. Vergani).
} 


\section{Nomenclature}

Symbol unit description

$E_{1}[\mathrm{MPa}] \quad$ Longitudinal elastic modulus of the lamina

$E_{2}[\mathrm{MPa}] \quad$ Transverse elastic modulus of the lamina

$E_{m}[\mathrm{MPa}] \quad$ Matrix elastic modulus

$E_{f}[\mathrm{MPa}] \quad$ Fibre elastic modulus

$F_{12} \quad$ Coefficient of Tsai-Wu criterion

$G_{12}$ [MPa] In-plane shear modulus of the lamina

$G_{m}[\mathrm{MPa}] \quad$ Matrix shear modulus

$G_{f}[\mathrm{MPa}] \quad$ Fibre shear modulus

$G_{x x}[\mathrm{MPa} / \mathrm{h}] \quad$ Slope of the double logarithmic plot of pressure vs time, from ASTM D2992

$I D[\mathrm{~mm}] \quad$ Inner or nominal diameter of the pipe

$\mathrm{MPR}_{\mathrm{xx}}[\mathrm{MPa}]$ Maximum pressure rating at the operating temperature $\mathrm{XX}^{\circ} \mathrm{C}$

$\begin{array}{ll}P[\mathrm{MPa}] & \text { Design pressure } \\ \mathrm{R} & \text { Ratio of hoop stress to axial stress (R-ratio) }\end{array}$

$\mathrm{R}_{\text {test }} \quad$ Selected value of the R-ratio for performing tests in accordance with ISO 14692

$S_{1}[\mathrm{MPa}] \quad$ Ultimate longitudinal tensile strength of the lamina

$S_{2}[\mathrm{MPa}$ Ultimate transverse tensile strength of the lamina

$S_{1}^{C}[\mathrm{MPa}] \quad$ Ultimate longitudinal compressive strength of the lamina

$S_{2}^{C}[\mathrm{MPa}] \quad$ Ultimate transverse compressive strength of the
$S_{12}[\mathrm{MPa}]$

$S_{m}[\mathrm{MPa}]$

$S_{m}^{c}[\mathrm{MPa}]$

$S_{f}[\mathrm{MPa}]$

$S_{f}^{c}[\mathrm{MPa}]$

$S_{12 m}[\mathrm{MPa}]$

$t_{r}[\mathrm{~mm}]$

$V_{f}$

$\left(\gamma_{12}\right)_{u l t}[\mu \mathrm{m} / \mathrm{m}]$ Ultimate in-plane shear strain of the lamina

$\left(\varepsilon_{1}\right)_{u l t}[\mu \mathrm{m} / \mathrm{m}]$ Ultimate longitudinal tensile strain of the lamina

$\left(\varepsilon_{2}\right)_{\text {ult }}[\mu \mathrm{m} / \mathrm{m}]$ Ultimate transverse tensile strain of the lamina

$\left(\varepsilon_{1}\right)_{u l t}^{C}[\mu \mathrm{m} / \mathrm{m}]$ Ultimate longitudinal compressive strain of the lamina

$\left(\varepsilon_{2}\right)_{u l t}^{C}[\mu \mathrm{m} / \mathrm{m}]$ Ultimate transverse compressive strain of the lamina

$\theta\left[^{\circ}\right] \quad$ Winding angle

$v_{12} \quad$ Major Poisson's ratio of the lamina

$v_{21} \quad$ Minor Poisson's ratio of the lamina

$v_{m} \quad$ Matrix Poisson ratio

$v_{f} \quad$ Fibre Poisson ratio

$\xi$, $\xi^{\prime} \quad$ Reinforcing factors of Halpin-Tsai model

$\sigma_{1}[\mathrm{MPa}] \quad$ Stress in the lamina along fibre direction

$\sigma_{2}[\mathrm{MPa}] \quad$ Stress in the lamina normal to fibre direction

$\sigma_{a}[\mathrm{MPa}] \quad$ Axial stress

$\sigma_{h}[\mathrm{MPa}] \quad$ Hoop stress

$\tau_{12}[\mathrm{MPa}] \quad$ In-plane shear stress in the lamina environment and from accidental scratches and impacts. However, focussing on the structural design of FRP pipes, the main layer providing resistance to high internal pressure is the reinforced composite, that is typically manufactured by filament winding. Therefore, all the calculations provided in this paper will refer to this layer, that is typically manufactured by filament winding.

Filament winding is a technological process developed in the late 1960s, that creates a helical pattern bio-mimicking the silk filament deposition in cocoon shape by the silkworm. This manufacturing technique is typically used to create hollow composite structures, such as pipes and vessels, by cross-weaving polymer-impregnated continuous rovings around a cylindrical mandrel. The use of continuous fibres ensures the

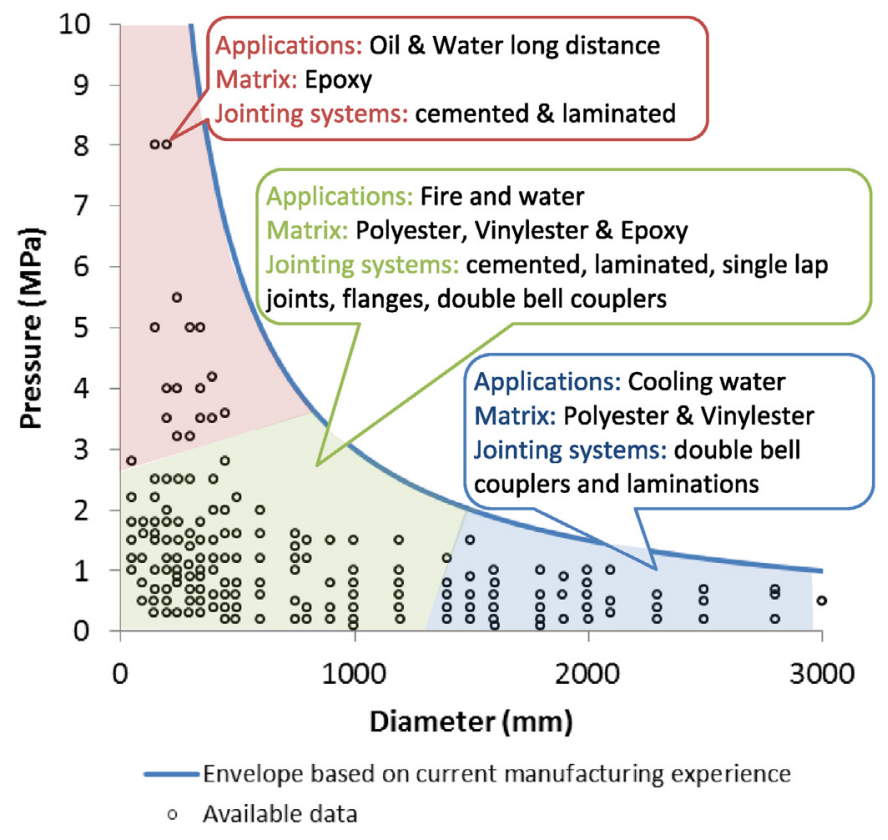

Fig. 1. State of the art of pipelines according with EN ISO 14692 [7] and [8]. uniformity in the direction of fibre arrangement; the use of a cylindrical mandrel ensures the consistency in the inside diameter of pipes [2]. The main parameter controlling the mechanical behaviour of the pipe is the angle of the fibres with respect to the longitudinal direction, which is called winding angle, $\theta$ (Fig. 2). This angle can be automatically controlled by the rotational speed of the mandrel and the longitudinal speed of the head dispensing the tows, i.e. the payout head. Among the pros of this technique, we can list: 1 ) the creation of a highly repetitive deposition pattern [10], with an easy deposition of fibre in a wide range of directions (typically between $20^{\circ}$ and $87^{\circ}$ ); 2) the possibility to obtain high volume fraction $V_{f}$;3) the curing process is easy and may not be carried out in autoclave; 4) the possibility to use not pre-impregnated fibres. On the other hand, some of the cons of this technique are: 1) it is limited to axialsymmetric shapes or similar and no concave shape can be manufactured; 2) the variation of the winding angle must be gradual; 3) the mandrel could be removable and its cost is relevant [11].

The design and qualification of FRP pipes, and more specifically those reinforced with glass fibres (GRP), are governed mainly by standards ([7] [12]) and industrial specifications. In particular, in the present paper we will refer to the ISO standard 14692 [7], dedicated to GRP pipes for petroleum and natural gas industries, which has been revised very recently. The assessment proposed by this standard compares the stress state of the pipe with the material mechanical properties, along hoop and axial direction by means of the failure envelope. Complete experimental envelopes, with sufficient data points to accurately describe the failure domain, are relatively few; an example is reported in Ref. [13] for pipes made of $\pm 60^{\circ}$ E-glass roving

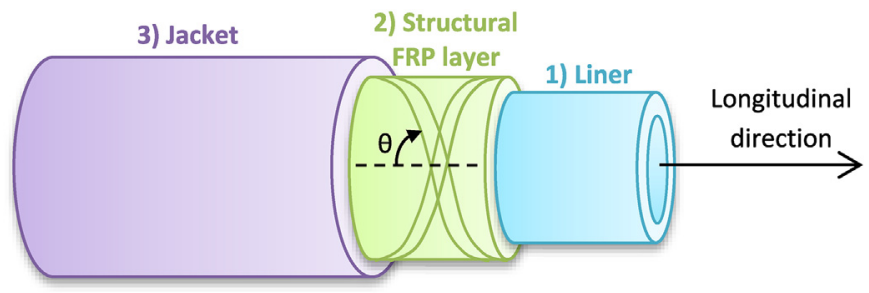

Fig. 2. Typical structure of a composite pipe. 
reinforcement and epoxy resin. Five different failure mechanisms occurred, as a function of the applied axial-to-hoop stress ratio: 1) tensile axial failure; 2) weepage; 3) local leakage; 4) burst; 5) compressive axial failure. Based on these, the authors of [13] plotted a failure envelope, both in stress and strain terms, and it was found to be fit by linear segments.

Regarding the evaluation of the specific stress state into the pipe, the basic formulas come from the "netting analysis" [14], based on the assumption that only fibres carry the loads and neglecting matrix strength. This theory suggests as an optimal winding angle $54.7^{\circ}$, and this was specifically indicated in the past version of the standard [15]. However, variations of axial loads, for instance caused by boundary conditions or changes in the operative conditions, can modify the stress state into the pipe. For this reason, the designer needs indications to estimate the best winding angle taking into account the stresses induced at the pipe wall, and potentially customize the pipe to the specific boundary conditions into the plant. This can avoid extra thickness manufacturing and transportation costs. This analysis is complex and the designer needs for a reliable and quick tool in the choice and optimization of the main material and technological parameters.

This paper aims to present an optimal and automatized design procedure of a plain pipe under inner pressure, according with ISO standard 14692 [7]. The focus is on the structural design of the only composite layer and on the mechanical strength of the pipe, thus neglecting the chemical standpoint, which can be addressed to the inner liner. This paper looks into the possibilities for high diameter GRP pipes being suitable for high pressure transmission systems and other applications within the oil \& gas transportation and distribution system.

Fig. 3 shows the flowchart of the work, developed in three parts.

The first step ("Lamina") regards the analytical estimation of elastic and strength properties of the lamina, from matrix and fibres' ones, based on some selected literature models. This section will provide indications for the selection of the best ratio between mechanical properties of matrix and fibres and on the volume fraction.

The second step ("Pipe Design") deals with the design of a plain pipe under inner pressure. In this component, the target is to minimize the wall thickness as a function of two main inputs, in addition to lamina and laminate properties: the volume fraction $V_{f}$ and the winding angle $\theta$.

The last step ("Standard") implements the requirements given in Ref. [7]; this part will focus on the influence of axial loads on the wall thickness, and on its dependency on the main parameters influencing the pipe strength.

The whole procedure is analytically implemented into a Matlab script. Indeed, the aim of the work is to provide the structural designer with a relatively fast and automatized procedure for defining the optimal design parameters of a GRP pipe, based on the standard requirements, and helpful for the preliminary selection of the manufacturer.
Table 1

Summary of the equations used in the estimation of the elastic properties of the lamina [17]. Subscripts 1 and 2 stand respectively for fibre and matrix (in plane transverse) directions.

\begin{tabular}{|c|c|c|c|}
\hline Property & Symbol & Equation & Model \\
\hline $\begin{array}{l}\text { Longitudinal } \\
\text { elastic } \\
\text { modulus }\end{array}$ & $E_{1}$ & $E_{1}=V_{f} E_{f}+\left(1-V_{f}\right) E_{m}$ & Mixture \\
\hline \multirow{3}{*}{$\begin{array}{l}\text { Transverse } \\
\text { elastic } \\
\text { modulus }\end{array}$} & $E_{2}$ & $E_{m}\left[1+\xi\left(\frac{E_{f}-E_{m}}{E_{f}+\xi E_{m}}\right) V_{f}\right]$ & \multirow[t]{3}{*}{$\begin{array}{l}\text { Halpin- } \\
\text { Tsai [18] }\end{array}$} \\
\hline & & $E_{2}=\frac{E_{f}-E_{m}}{1-\left(\frac{E_{f}+\xi E_{m}}{E_{m}}\right) V_{f}}$ & \\
\hline & & $\begin{array}{l}\text { with } \xi=1.55 \text { reinforcing factor, } \\
\text { accounting for fibre geometry, packing } \\
\text { geometry and loading conditions }\end{array}$ & \\
\hline \multirow{3}{*}{$\begin{array}{l}\text { In-plane } \\
\text { shear } \\
\text { modulus }\end{array}$} & $G_{12}$ & $G_{m}\left[1+\xi\left(\frac{G_{f}-G_{m}}{G_{f}+\xi G_{m}}\right) V_{f}\right]$ & \multirow[t]{3}{*}{$\begin{array}{l}\text { Halpin- } \\
\text { Tsai [18] }\end{array}$} \\
\hline & & 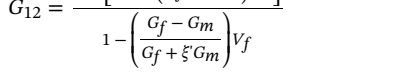 & \\
\hline & & $\begin{array}{l}\text { with } \xi^{\prime}=1 \text {, supposing fibres with } \\
\text { circular cross section }\end{array}$ & \\
\hline $\begin{array}{l}\text { Major } \\
\text { Poisson's } \\
\text { ratio }\end{array}$ & $\nu_{12}$ & $\nu_{12}=\nu_{f} V_{f}+\nu_{m}\left(1-V_{f}\right)$ & Mixture \\
\hline
\end{tabular}

\section{Step 1: Lamina}

When facing the mechanical design of a composite pressure vessel, the first step of the procedure refers to the calculation of the mechanical properties of the lamina, starting from the selection of the single constituents, e.g. fibre and matrix. At the bid stage, the designer often does not have detailed experimental information on laminas or laminates, because the availability of fibres and of matrices is wide. Several analytical and semi-empirical models based on micromechanics exist in the literature for the estimation of both elastic and strength properties which characterise a composite lamina, e.g. Ref. [16]. Table 1 and Table 2 summarize the criteria we selected and implemented into a Matlab script for estimating lamina properties.

As an alternative, the designer can also use the outputs of specific pre-implemented software, as Autodesk ${ }^{\star}$ Helius Composite. Later on, the selection of the most appropriate model should be validated by experimental tests.

The main assumptions at the basis of the implemented models are: 1) matrix and fibre have a linear elastic behaviour up to failure; 2) matrix and fibre are homogeneous and singularly isotropic; 3) matrix and fibre are in perfect adhesion each other.

Among composite properties, the estimation of the ultimate transverse tensile strength $S_{2}$ is quite complicated. Indeed, under a transverse tensile load, not only the individual properties of fibre and matrix are important, but also other factors difficult to analytically estimate, such as bond strength between fibre and matrix, presence of voids, and presence of residual stresses due to thermal expansion mismatch

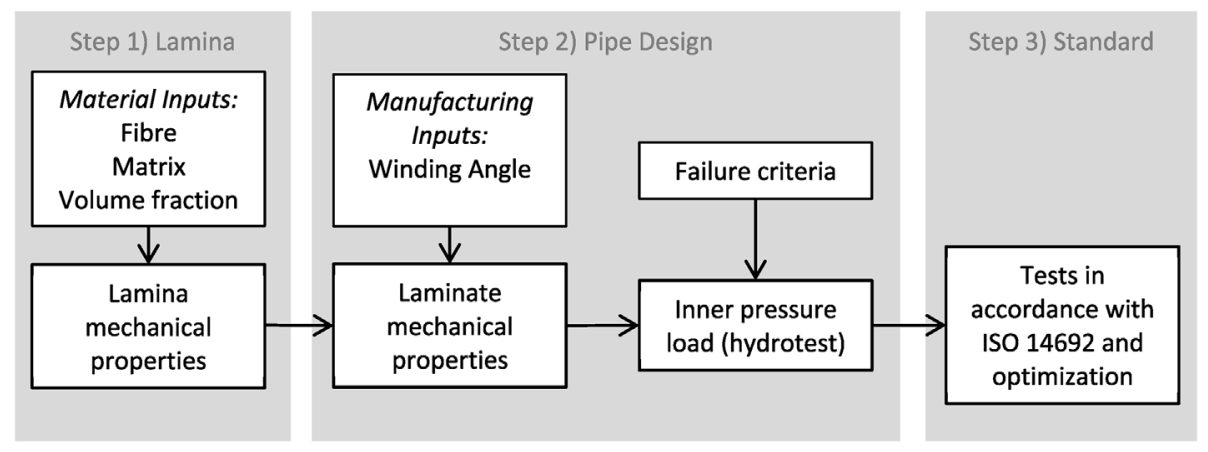

Fig. 3. Flowchart of the work. 
Table 2

Summary of the equations used in the estimation of the strength properties of the lamina [19].

Fail strains can be obtained from these stresses supposing the lamina behaviour linear up to failure.

\begin{tabular}{|c|c|c|c|}
\hline Property & Symbol & Equation & Model \\
\hline $\begin{array}{l}\text { Ultimate longitudinal } \\
\text { tensile strength }\end{array}$ & $S_{1}$ & $S_{1}=S_{f} V_{f}$ & Fibre tension \\
\hline $\begin{array}{l}\text { Ultimate transverse } \\
\text { tensile strength }\end{array}$ & $S_{2}$ & $S_{2}=\left[1-\left(\sqrt{V_{f}}-V_{f}\right)\left(1-\frac{E_{m}}{E_{f}}\right)\right] S_{m}$ & Chamis \\
\hline $\begin{array}{l}\text { Ultimate longitudinal } \\
\text { compressive strength }\end{array}$ & $S_{1}^{c}$ & $\left|S_{1}^{c}\right|=V_{f} \cdot\left|S_{f}^{c}\right|$ & Fibre compression \\
\hline $\begin{array}{l}\text { Ultimate longitudinal } \\
\text { transverse strength }\end{array}$ & $S_{2}^{c}$ & $\left|S_{2}^{c}\right|=\left[1-\left(\sqrt{V_{f}}-V_{f}\right)\left(1-\frac{E_{m}}{E_{f}}\right)\right]\left|S_{m}^{c}\right|$ & Chamis \\
\hline $\begin{array}{l}\text { Ultimate in-plane } \\
\text { shear strength }\end{array}$ & $S_{12}$ & $S_{12}=\left[1-\left(\sqrt{V_{f}}-V_{f}\right)\left(1-\frac{G_{m}}{G_{f}}\right)\right] S_{12 m}$ & Chamis \\
\hline
\end{tabular}

between the fibres and the matrix [17]. Therefore, the estimation of the composite strength in the transverse direction, which is the main mechanical characteristic needed for defining the weepage failure mode, is a very important parameter which must be cross-checked with accurate numerical or experimental data.

Therefore, focussing on the transverse strength $S_{2}$, we propose the plot in Fig. 4. This contour plot shows the value of transverse strength $S_{2}$, normalized with respect to the matrix strength $S_{m}$, as a function of the ratio $E_{f} / E_{m}$ and of the volume fraction $V_{f}$. Note that this plot is the same for $S_{2}^{c} / S_{m}^{c}$ and for $S_{12} / S_{12 m}$, providing that the Chamis formulation is used (according with Table 2). Fig. 4 underlines that there is a region between $V_{f}=20-40 \%$ where $S_{2}$ is lower, thus meaning that fibre content should be increased as much as possible, to improve $S_{2}$ and avoid weepage. This is a quite low fibre content that can be easily avoided by an appropriate manufacturing technique. Indeed, the typical fibre content $V_{f}$ that can be reached by filament winding is in the range between 60 and 70\% [20], with even higher peaks (for instance, $V_{f}=72 \%$ in Ref. [13]). Thus selecting this manufacturing technique is an appropriate choice, because it allows the volume fraction to be far from the minimum transverse strength. Further comments on the optimal fibre content will be given in the next section.

The normalizing ratio $E_{f} / E_{m}$ used in Fig. 4 allows generalizing these comments for different matrices and fibres. In this work we will focus on an application of the pipe in the oil\&gas field, where the selection of these two constituents is important not only for the mechanical properties but also from the chemical viewpoint. Even if an inner layer is present and acts as a chemical barrier with respect to the inner fluid (see Fig. 2), fibres and matrixes must not degrade due to the permeation of chemical aggressive elements. Different long fibres can be used by the filament winding in roving or tape shapes. For this work, we selected glass fibres, and in particular on the E-CR grade fibres, especially designed for chemical resistance. On the other hand, we selected an epoxy matrix, which allows for relatively high mechanical properties. The paper will present analytical simulations considering data extrapolated from the material database CES EduPack ${ }^{\circ} 2016$. These fibres and matrix have a ratio $E_{f} / E_{m}$ equal to 35 .

Given these fibres and matrix, and with the aim of providing an optimization design tool, we plot in Fig. 5 the estimated analytical trends of the elastic and strength properties of the lamina, according with the selected models (Tables 1 and 2). In the figures, the outputs from the software Helius Composite are also used for a comparison; maximum percentage differences are around $10 \%$ (in the estimation of $\left.E_{2}\right)$.

Fig. 5 a shows the elastic properties normalized as a function of the matrix ones $\left(E_{m}\right.$ and $\left.G_{m}\right)$, i.e. when $V_{f}=0$ the curves start from 1 . This and the following plots are presented with $V_{f}$ between 10 and $80 \%$, which are the most used volume fractions in practical applications.

Fig. $5 \mathrm{~b}$ shows the lamina strengths normalized with respect to the fibre $\left(S_{f}\right.$ and $\left.S_{f}^{c}\right)$ or matrix $\left(S_{m}, S_{m}^{c}\right.$, and $\left.S_{12 m}\right)$ strengths. Focussing on the

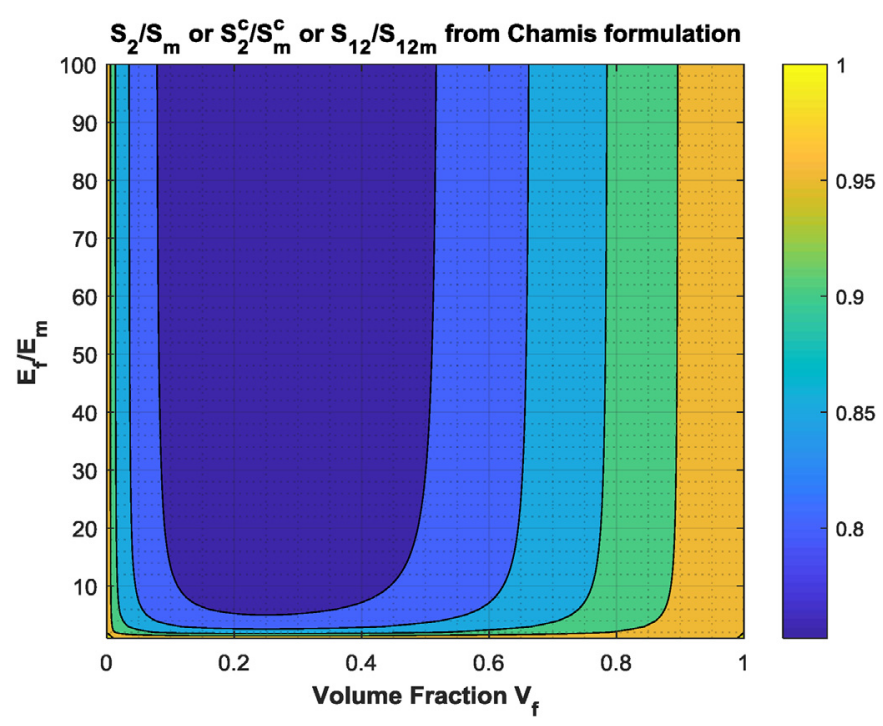

Fig. 4. Trend of $S_{2} / S_{m}$ or $S_{2}^{c} / S_{m}^{c}$ or $S_{12} / S_{12 m}$ as a function of the ratio $E_{f} / E_{m}$ and of the volume fraction $V_{f}$, according with Chamis formulation [19].

trend of $S_{2} / S_{m}$ and using Chamis [19] formulation, we have the trend of Fig. 4 for $E_{f} / E_{m}=35$. As previously commented, there is a minimum at $V_{f}=25 \%$, then $S_{2}$ increases with fibre content.

\section{Step 2: Pipe design}

Once the mechanical properties of the lamina are estimated, the second step of the design is to consider the laminate and to estimate its mechanical properties. Typically, the laminate is built during the manufacturing of the structural component, i.e. in our case the pipe. For this reason, in this section we will briefly recall the laminate macromechanics and we will provide an overview of the classical failure criteria to be used in the composite pipe assessment. Finally, we will provide an analytical tool for the assessment of a plain pipe under the simple inner pressure.

\subsection{Macromechanics and failure criteria}

Given the main lamina properties, we implemented the classical equations of macromechanics of the lamina, under the hypothesis of orthotropy (i.e. by considering as main variables $E_{1}, E_{2}, v_{12}$ and $G_{12}$ ). Then, we investigated the overall mechanical behaviour of the laminate by the macromechanics of the laminate (Classical Lamination Theory) [21]. In order to implement this theory, we need: 1 ), the mechanical behaviour of the lamina, taken from Fig. 5; 2) the orientation of each layer; 3) its thickness. 
a.

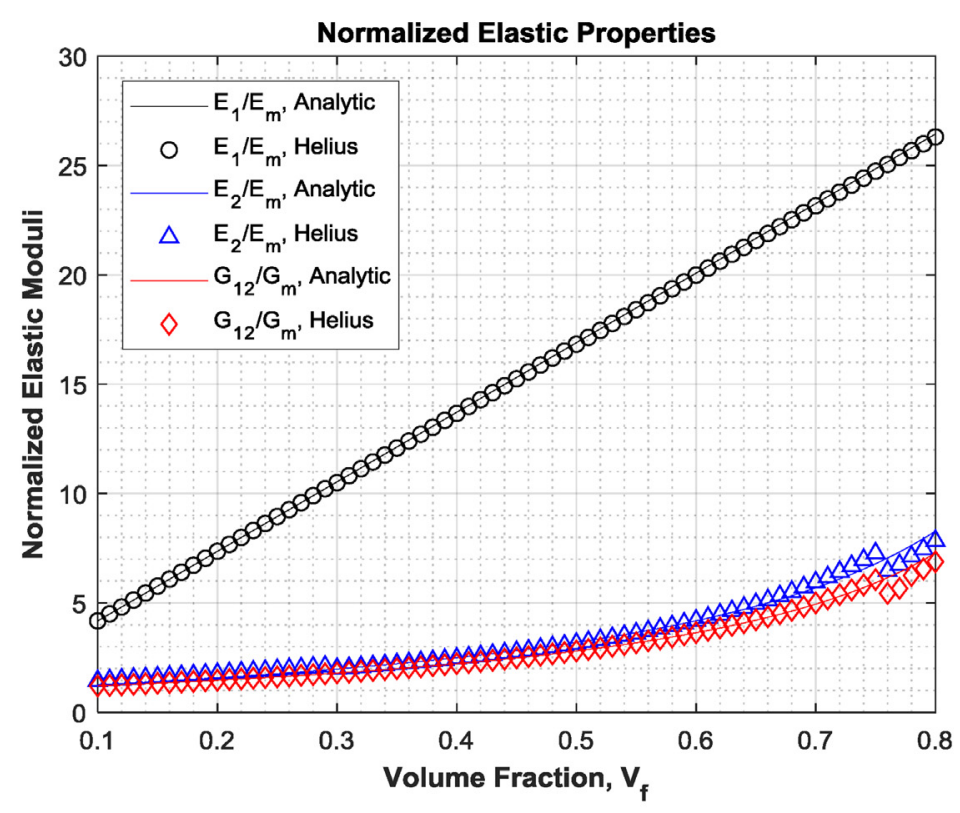

Input:

E-CR fibre

Epoxy matrix

$E_{f} / E_{m}=35$

$\mathrm{G}_{\mathrm{f}} / \mathrm{G}_{\mathrm{m}}=40$

b.

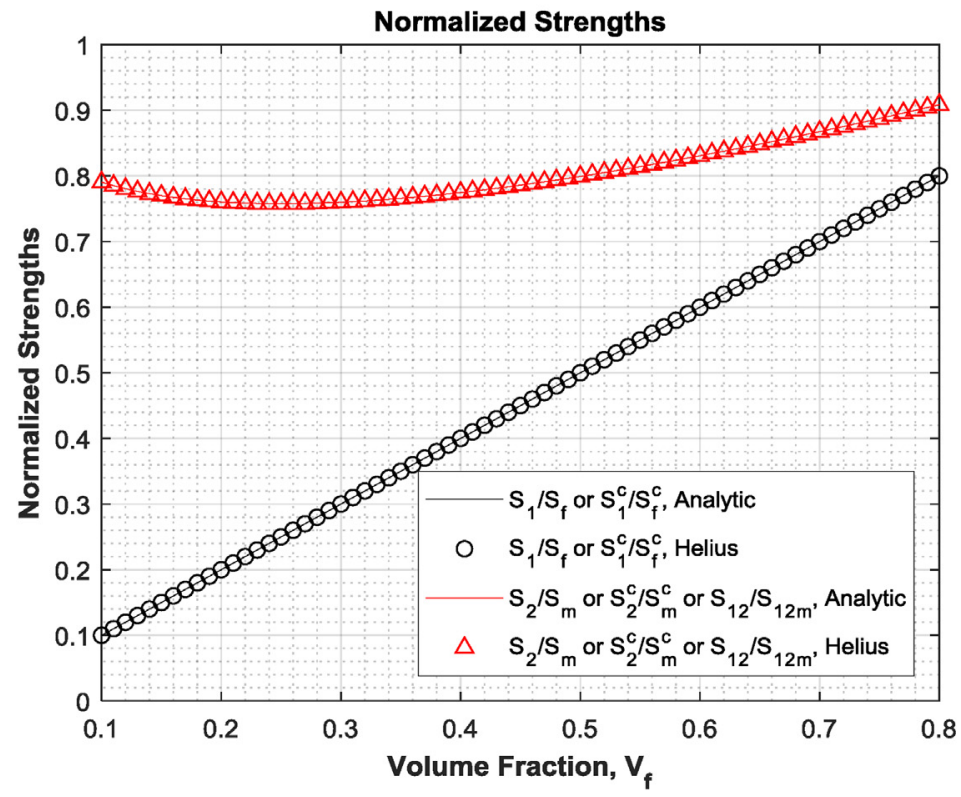

Input:

E-CR fibre

Epoxy matrix

$E_{f} / E_{m}=35$

$\mathrm{G}_{\mathrm{f}} / \mathrm{G}_{\mathrm{m}}=40$

Fig. 5. Analytical estimations of elastic (a.) and strength (b.) properties of the lamina and comparison with the results of the software Helius Composite.

Finally, the failure of each lamina should be assessed according to a proper failure criterion. Table 3 shows the failure criteria we implemented into the Matlab script, i.e. the maximum stress criterion, the maximum strain criterion, the Tsai-Hill and the Tsai-Wu criteria [17]. In addition to these general failure criteria, we implemented also the Puck formulation [22], including the inter-fibre fracture (IFF) and the related failure modes. This specific criterion can offer a wider interpretation of the failure mode effectively occurring in the matrix. The positive assessment of the laminate occurs when all these failure criteria are satisfied for all the laminas, i.e. the first ply failure. In this way, different failure modes are considered in the meantime, along fibre and matrix directions (and especially weepage mode, which is the most frequent in these components [23]). Other types of damage, such as delaminations or failure at the interface between fibre and matrix, are beyond the aim of this work, which focuses on the design rather than the final assessment of the pipe. We can here recall briefly some literature works specific for these failure modes [24] [25] [26].

\subsection{Simulation of the hydrotest: state of stress and assessment of the pipe}

The stresses raising into a plain pipe due to the only inner pressure (hydrotest condition) are:

- the axial stress: $\sigma_{a p}=\frac{p \cdot I D}{4 t_{r}}$

- the hoop stress: $\sigma_{h p}=\frac{p \cdot I D}{2 t_{r}}$

where $I D$ is the inner diameter and $t_{r}$ is the reinforced wall thickness. For structural purposes, we will consider only the net reinforced thickness of the pipe wall, excluding the resin rich layer. These are Mariotte's equations, valid for small thickness, i.e. $\frac{t_{r}}{D}<0.1$. However, since the pipe systems are locally supported, the state of stress may vary 
Table 3

Implemented failure criteria for the composite laminas [17] [22].

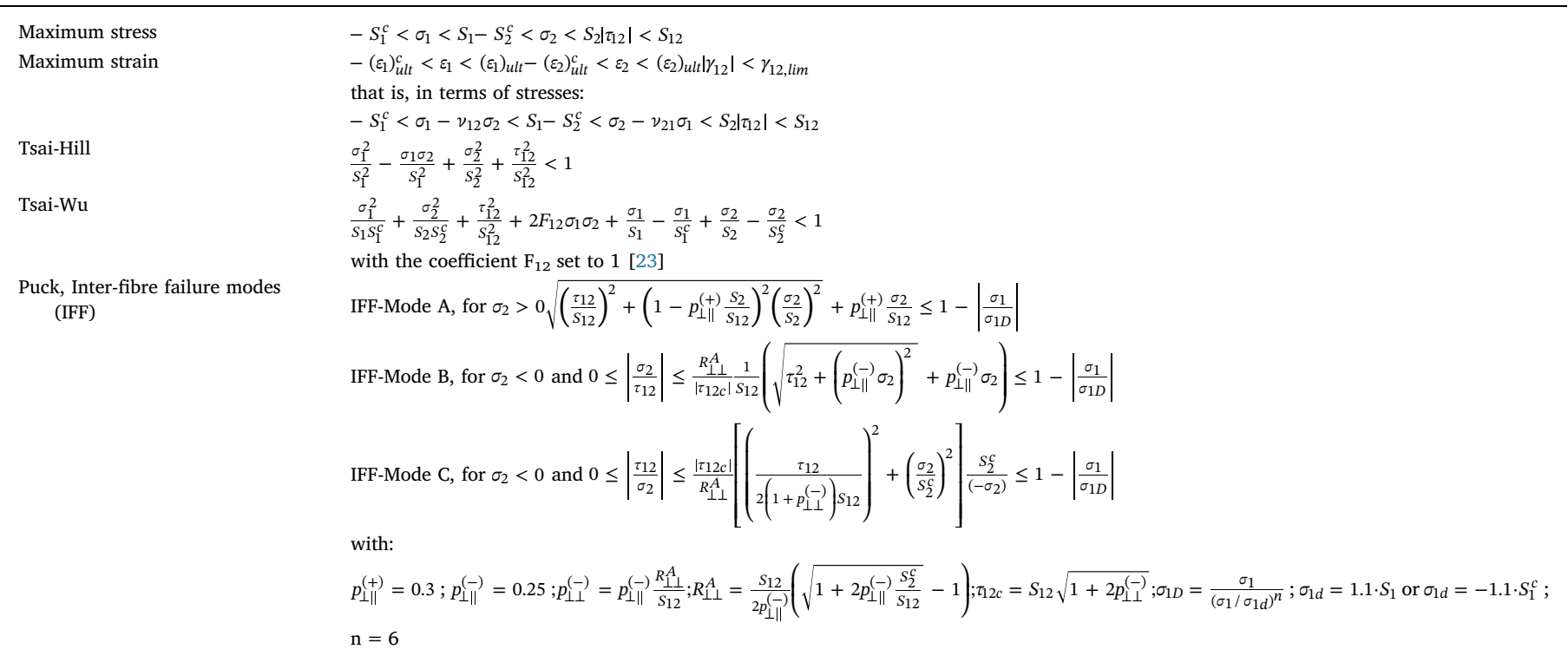

depending on the boundary constraints. More in general, it is possible to define overall the state of stress of pipe wall introducing the ratio $R$, defined as:

$R=\sigma_{h}: \sigma_{a}$

where $\sigma_{h}$ and $\sigma_{a}$ are the overall hoop and axial stresses acting in pipe due to pressure and to the constraints. The two extreme loading cases for unrestrained conditions are:

1 ) open pipe, $R=1: 0$; the pipe is long and has no top and bottom closures, therefore the inner pressure generates only the hoop stress $\sigma_{h p}$, while the axial stress is null. This condition rarely happens in practical cases;

2) closed pipe, $R=2: 1$; the longitudinal displacement is allowed, with the combined presence of $\sigma_{a p}$ and $\sigma_{h p}$.

The presence of axial constraints along the pipe may modify $R$, that can assume values between these two cases.

At first we implemented into the Matlab script the hydrotest case with $R=2: 1$. The loading condition is limited to a structural static simulation and no material degradation as a function of time is taken into account, since in the design stage we aim to offer the designer a quick but reliable tool for the choice of the main parameters. Further indications will be given in the next section.

Starting from a close-to-zero wall thickness, the script calculates the corresponding state of stress. Then, it applies the failure criteria of Table 3; if even one of the failure criteria is not satisfied, the software increments the thickness. The process is repeated until all the failure criteria are satisfied, i.e. the inverse of the safety coefficient (failure index) is smaller than 1 . When the iterative process increases the thickness, it considers the pattern drawn by the filament winding adding 2 layers per time, corresponding to $\pm \theta^{\circ}$ winding angled plies. So, the full laminate is composed by couples of plies placed at $\pm \theta^{\circ}$ winding angle, whose value $\theta$ is constant. We do not consider the woven manufacturing of the bands of roving layers, which is the effective fibre wrapping obtained by means of the filament winding. This means that we simplified the lamina structure considering only unidirectional layers at + and $-\theta^{\circ}$. This choice can be considered conservative and it is generally accepted in the composite literature, as for instance mentioned in Ref. [27].

The degrees of freedom to be considered as inputs for the hydrotest can be: 1) the inner diameter $I D, 2)$ the inner pressure $p, 3)$ the volume fraction $V_{f}$ and 4) the winding angle $\theta$. It is worth noting that the first two parameters, $I D$ and $p$, have a linear influence, providing the small thickness hypothesis is satisfied. More interesting is the influence of $V_{f}$ and $\theta$ on the minimum reinforced wall thickness $t_{r}$.

Fig. 6 shows the influence of $V_{f}$ on $t_{r}$. Values are normalized with respect to the maximum estimated $t_{r}$ at $V_{f}=10 \%$. The minimum reinforced wall thickness of the pipe is highly dependent on the analytical model used in the estimation of the transverse tensile strength, governing pipe weepage [23]. The same plot also shows a comparison between analytical estimations and results from Helius Composite, which allows for simulations of composite elements with simple geometries as the pipe. The two trends are very similar. For the selected matrix and fibre, the optimizing value of fibre content, i.e. in correspondence of the minimum wall thickness, is between 45 and $65 \%$, where the trend of $t_{r}$ is flat.

Fig. 7 shows the dependence of $t_{r}$ with respect to the winding angle

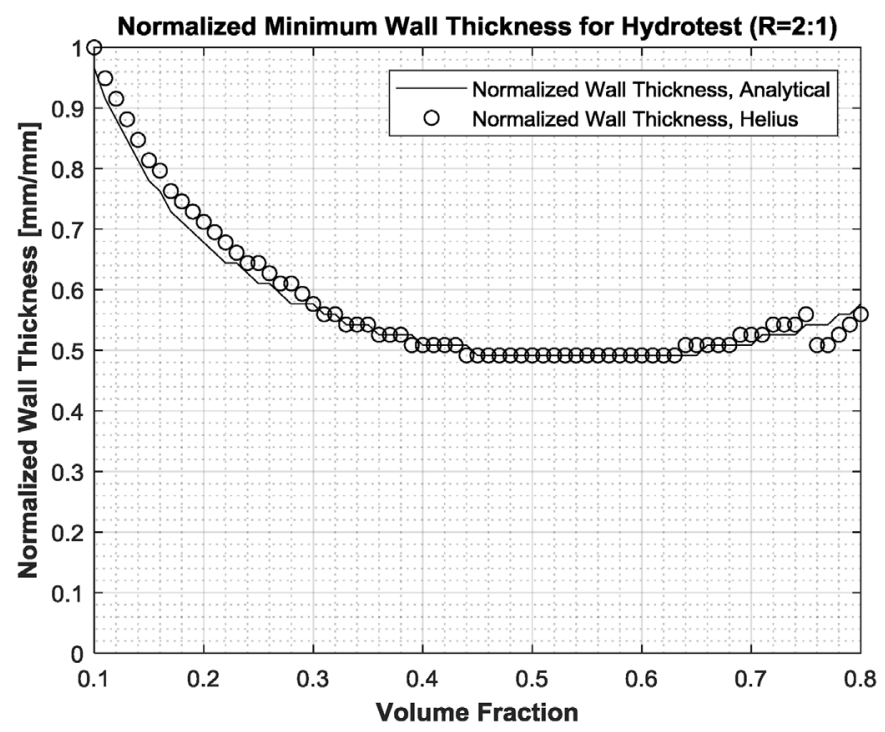

Fig. 6. Normalized trend of minimum pipe thickness $t_{r}$ with respect to the volume fraction $V_{f}$ : hydrotest with $\mathrm{R}=2: 1$, winding angle $\theta= \pm 55^{\circ}$. Values are normalized with respect to the maximum estimated $t_{r}$ at $V_{f}=10 \%$. 


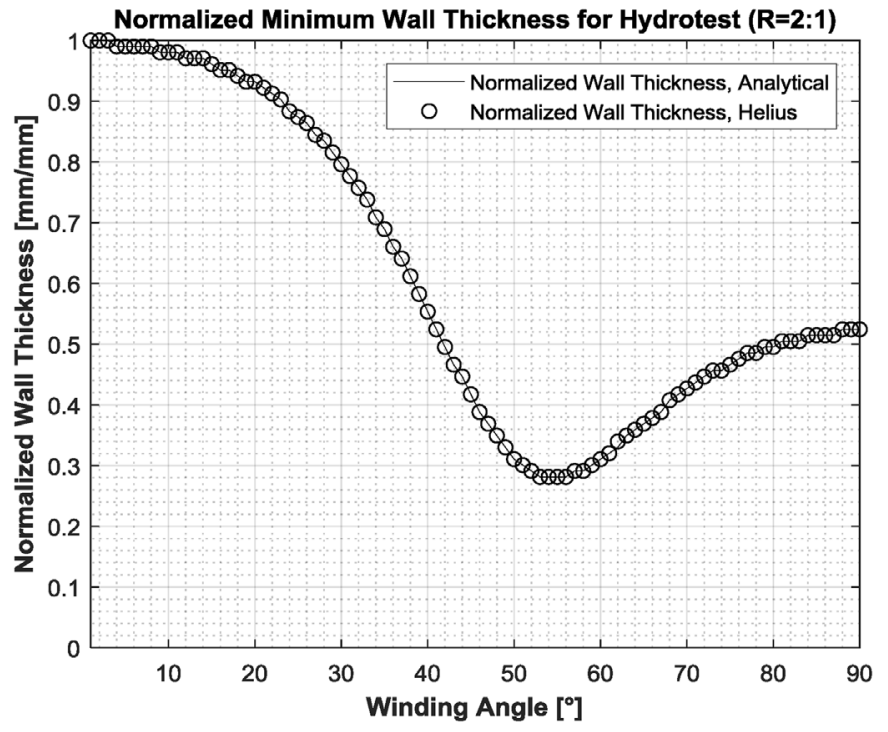

Fig. 7. Normalized trend of minimum pipe thickness $t_{r}$ with respect to the winding angle $\theta$ : hydrotest with $R=2: 1$, volume fraction $V_{f}=60 \%$. Values are normalized with respect to the maximum estimated $t_{r}$ at $\theta=0^{\circ}$.

$\theta$. Values are normalized with respect to the maximum estimated $t_{r}$ at $\theta=0^{\circ}$. The winding angle for a loading ratio $R=2: 1$, which minimizes the wall thickness, is proved to be $\pm 55^{\circ}$, in accordance with [28]. This value of the winding angle $\left( \pm 55^{\circ}\right)$ optimizes the resistance of the composite to the stress state condition given from the inner pressure. This optimal value shall vary if other stress states are considered, as will be commented in the next section, but it is not dependant on the pressure, diameter, or volume fraction.

These two considerations on the optimal $V_{f}$ and $\theta$ are also visible in Fig. 8, showing the mutual influence of these parameters on the minimum reinforced wall thickness $t_{r}$ by a contour map. In this plot, values are normalized with respect to the maximum estimated $t_{r}$ at $\theta=0^{\circ}$ and $V_{f}=10 \%$. Based on these considerations, we will work with $V_{f}=60 \%$ and $\theta= \pm 55^{\circ}$, but further comments on the optimal winding angle will be given in the next section.

\section{Step 3: Standard}

This last step of the work regards the implementation of the ISO 14692 requirements into the script. After studying in the second step the influence of the volume fraction and of the winding angle for a fixed loading ratio, here we consider the loading ratio $\mathrm{R}$ as a further variable. This step aims to simulate the design and qualification of the pipe for the final industrial application. All the quantities mentioned in this section are in accordance with the nomenclature given in ISO 14692-1.

The standard prescribes the assessment based on the qualified pressure and on the qualified stress. The design in accordance with the qualification programme is valid if:

1) the selected maximum pressure rating at the operating temperature (named $\mathrm{MPR}_{\mathrm{xx}}$ ) generates a long term failure envelope, estimated from ASTM D2992 [29], wide enough to contain all the States of Stress (SoS). The failure envelope is a simplified region in the $\sigma_{h}-\sigma_{a}$ plot limited by linear segments. The area of the failure envelope depends on the $M P R_{x x}$ and on the gradient $G_{x x}$ that identifies the material decay during time (i.e. it is the slope of the double logarithmic plot of inner pressure that the pipe has to withstand vs the operating time) following ASTM D2992;

2) the long term failure envelope, function of $M R_{x x}$, is validated by two mandatory survival tests, i.e. the survival pressure test in $\mathrm{R}=2: 1$ condition, unrestrained ends, for a time that can be selected from 1000 up to $6000 \mathrm{~h}$, and the survival pressure test in $\mathrm{R}=\mathrm{R}_{\text {test }}$ condition at $1000 \mathrm{~h}$. $\mathrm{R}_{\text {test }}$ is a particular value of the R-ratio (see Eq. (1)), to be fixed between 0.5 and 1 . Both these tests must be performed in accordance with ASTM D1598 [30] at the operating temperature.

Once the materials of the pipe are selected, $M P R_{x x}$ and $R_{\text {test }}$ are the two main parameters influencing area and shape of the failure envelope. The introduction of the $R=R_{\text {test }}$ mandatory survival test represents a news of ISO 14692 and obliges the designer to manufacture a pipeline which shall be able to withstand axial loads, even if these loads are not listed in the demand request or are unknown. The choice of the most appropriate $M P R_{x x}$ and $R_{\text {test }}$ is performed in order to have all the states of stress included into the related failure envelope. More in details, the $M P R_{x x}$ is an area amplifier, while $R_{\text {test }}$ is a shape modifier of the long term failure envelope. Fig. 9 reports an example: the higher is $R_{\text {test }}$, the smaller is the failure envelope, i.e. $R_{\text {test }}$ close to 1 is a conservative choice. The designer shall determine the most suitable values of $\mathrm{MPR}_{\mathrm{xx}}$ and $\mathrm{R}_{\text {test }}$ taking into account the following considerations:

- an increment of $\mathrm{MPR}_{\mathrm{xx}}$ rises the pressures used for survival test, and so the thickness needed to withstand this increase in pressure. This increment influences the cost of the pipeline. Therefore, $M_{P R}$ should be selected as lower as possible;

- a low value of $R_{\text {test }}$ increases the pressure of the $R_{\text {test }}$ survival test, and so the thickness and the cost of the pipe.

Based on these considerations, we implemented a Matlab script to automatize the qualification procedure of ISO 14692. The main steps are:

- definition of the design data, based on the design requests;

- bid process;

- initial estimation of the reinforced wall thickness;

- definition of loading cases and calculation of State of Stress points (SoS) by means of the stress analysis;

- choice of the $M_{P R}$ and the $R_{\text {test }}$, by means of the comparison between the design envelopes and the State of Stress points;

- validation of the $\mathrm{MPR}_{\mathrm{xx}}$

- evaluation of the parameters for the survival validation tests: - $\mathrm{R}=2: 1$, estimating the pressure for the hydrotest;

- $\mathrm{R}=\mathrm{R}_{\text {test }}$, estimating the pressures to be applied to the pipe in the

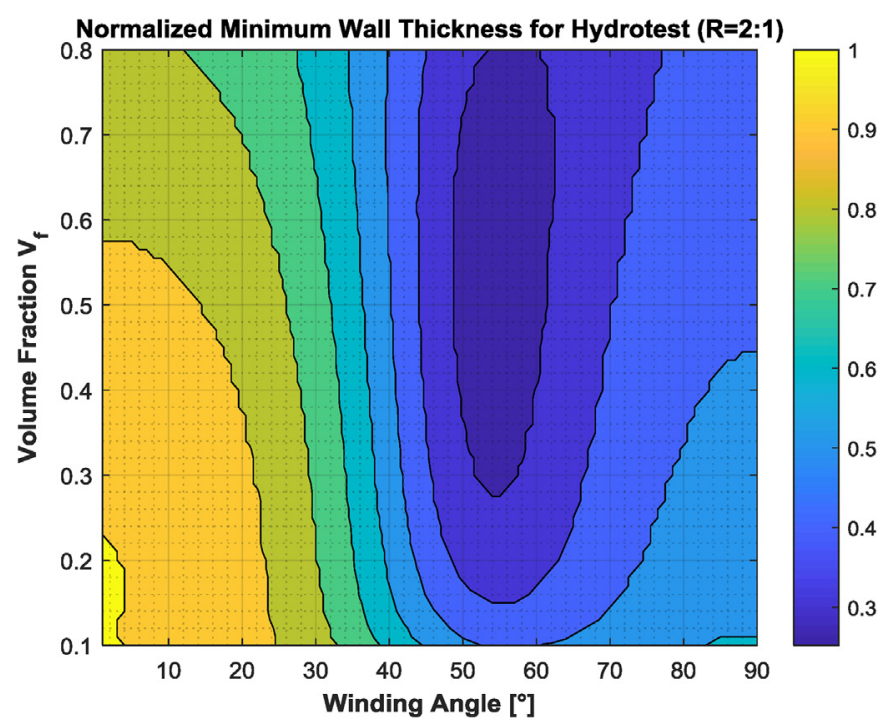

Fig. 8. Normalized trend of minimum pipe thickness $t_{r}$ with respect to the volume fraction $V_{f}$ and the winding angle $\theta$. Values are normalized with respect to the maximum estimated $t_{r}$ at $\theta=0^{\circ}$ and $V_{f}=10 \%$. 


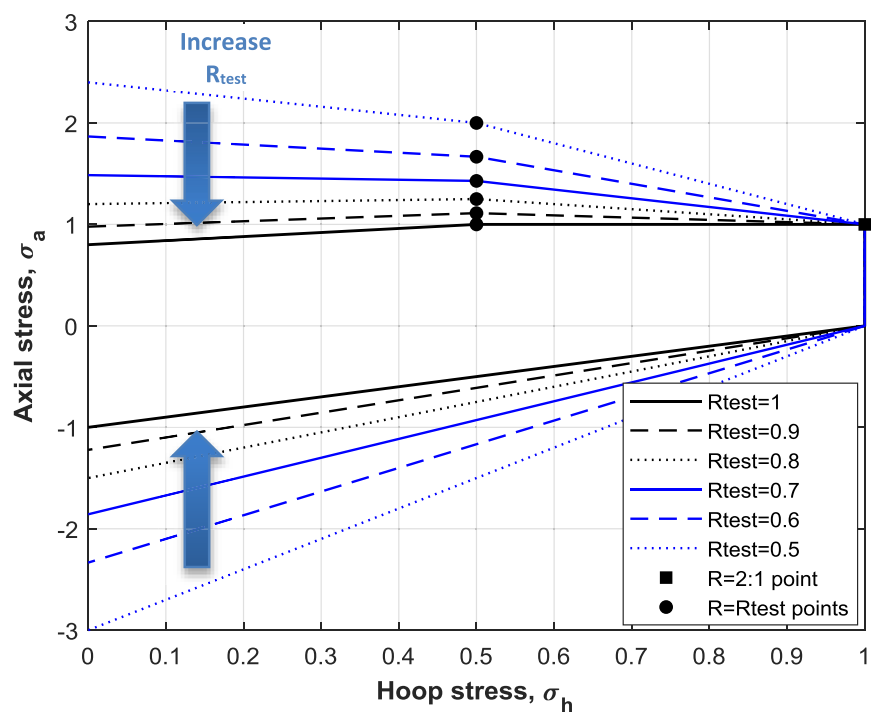

Fig. 9. Influence of $\mathrm{R}_{\text {test }}$ on the shape of the long term failure envelope. Values are normalized based on $\mathrm{R}=2: 1$ condition of the curve with $\mathrm{MPR}_{\mathrm{xx}}=1 \mathrm{MPa}$.

configuration prescribed by ASTM D1598. This standard, indeed, prescribes tests with not only inner pressure, but also its combination with axial loads, using a particular equipment with two pressure chambers as described in BS EN ISO 14692-2, Annex C.3.2.

The States of Stress (SoS) taken into account are: 1) SoS due to the design pressure - Sustained load, and 2) SoS due to the hydrotest at 1.5 times the design pressure - Occasional load. The relative position of these SoS points with respect to the long term failure envelope is function of $M P R_{\mathrm{xx}}$, but it is wall thickness independent.

Fig. 10 shows different design envelopes, normalized as a function of the $\mathrm{R}=2: 1$ condition (see also Fig. 9). The outer long term failure envelope is progressively scaled depending on the load type (occasional or sustained). Each failure envelope must contain the corresponding SoS point. For instance, the two SoS in Fig. 10 allow for a positive assessment of the pipe because the point corresponding to the design state is included into the design envelope for sustained loads, and the

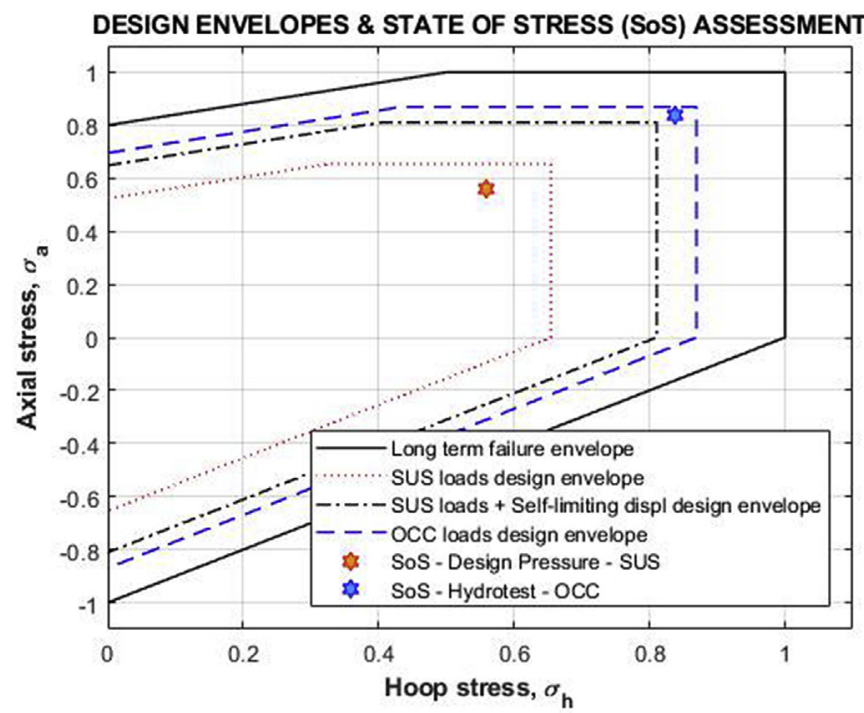

Fig. 10. Failure and design envelopes and examples of states of stress in accordance with ISO 14692. Values are normalized based on $R=2: 1$ condition of the unscaled long term failure envelope evaluated with $R_{\text {test }}=1$. Type of load: SUS $=$ sustained; OCC $=$ occasional. point corresponding to the hydrotest is included into the occasional design envelope. Once this assessment is satisfied, the designer can also determine the family of products qualified by this pipe, i.e. pipes with lower pressure and constant diameter, or pipes with lower diameter and constant pressure.

The script simulates the following qualification tests: 1 ) the validation of the $\mathrm{MPR}_{\mathrm{xx}} ; 2$ ) the survival test $\mathrm{R}=2: 1 ; 3$ ) the survival test $\mathrm{R}=\mathrm{R}_{\text {test }}$. Each simulation represents a constraint to the minimum wall thickness. The final thickness is the minimum thickness which validates all these 3 tests, i.e. the minimum between:

$-t_{r 1}$ : this value is estimated from the hydrotest performed to validate the $\mathrm{MPR}_{\mathrm{xx}}$. Starting from the long term hydrotest pressure based on the default service lifetime of 20 years, we can transpose it to the required design service life, and, finally, transposing it at $1000 \mathrm{~h}$. Indeed, the standard supposes that the degradation of the composite is linear in the double logarithmic plot inner pressure vs operating time. In this way, the validation of $\mathrm{MPR}_{\mathrm{Xx}}$ corresponds to an hydrotest at higher pressure but for a shorter time, thus compensating the degradation of the composite during time;

$-t_{r 2}$ : this value is estimated simulating the survival hydrotest ( $\mathrm{R}=2: 1)$ in accordance with the ASTM D1598. This standard allows to perform the $\mathrm{R}=2: 1$ hydrotest over a range of time from $1000 \mathrm{~h}$ to $6000 \mathrm{~h}$, changing the test pressure; in the following, we simulate the $1000 \mathrm{~h}$ test;

$-t_{r 3}$ : this is the minimum reinforced wall thickness for the selected $\mathrm{R}_{\text {test }}$.

Due to the $\mathrm{R}=\mathrm{R}_{\text {test }}$ pressure test, the implementation of the optimal angle for hydrotest condition, which is $\theta= \pm 55^{\circ}$, may not be the best choice. Therefore, the script identifies the value of winding angle $\theta$ which minimizes the pipe reinforced wall thickness by considering at the same time the three constraint tests above mentioned.

Fig. 11 describes the selection of the optimal winding angle. The normalized minimum reinforced thickness is plotted as a function of two variables: the winding angle $\theta$ and the $R_{\text {test }}$ (included in the range $0.5-1$, in accordance with the standard). This plot shows the two hydrotests with trend as in Fig. 7; their curves are almost overlapped. The curves for the $M P R_{x x}$ validation and the $R=2: 1$ survival hydrotest depend on the $\mathrm{MPR}_{\mathrm{xx}}$ value and on the $\mathrm{G}_{\mathrm{xx}}$ gradient. Fig. 11 also plots the trends of the normalized thickness for the $R=R_{\text {test }}$ pressure test $\left(t_{r 3}\right)$, for different $R_{\text {test }}$ values. The curves of the $R=R_{\text {test }}$ pressure test depend on the $M P R_{x x}$, on the $G_{x x}$, and strongly on the $R_{\text {test }}$ chosen, which directly influences the state of stress.

Referring only to the two hydrotests, the optimal winding angle is known to be $\pm 55^{\circ}$. Since the same pipe must also withstand to the $\mathrm{R}=\mathrm{R}_{\text {test }}$ pressure test, this value raises. The lowest relative thickness which contemporary optimizes the three tests (the hydrotest for $\mathrm{MPR}_{\mathrm{xx}}$ validation, the $R=2: 1$ hydrotest and the $R_{\text {test }}$ pressure test) is the intersection of these curves. It identifies a locus of optimal points minimizing the relative thickness $t_{r}$ required for all the tests in ISO 14692 , with winding angle variable in the range: $\pm 44.5^{\circ}<\theta< \pm 52.5^{\circ}$. It is worth mentioning that if the designer keeps $\theta= \pm 55^{\circ}$, in the worst case of $R_{\text {test }}=0.5$ the normalized thickness is 0.67 , compared with the optimized case of $\theta= \pm 44.5^{\circ}$ and normalized thickness 0.44 . This means an increase in thickness higher than $50 \%$.

Moreover, we can point out that the plot of Fig. 11 is valid for any pipe, because:

- the pressures of the survival tests for the validation of the $R=2: 1$ and $R=R_{\text {test }}$ depend on $M P R_{x x}, R_{\text {test }}$, and $G_{x x}$;

- $\mathrm{MPR}_{\mathrm{xx}}$ does not change the relative position of the curves related to the three mandatory tests;

$-G_{x x}$ is a default value function only of the selected matrix type. This value does not modify the relative position of the slopes generated by the $R=2: 1$ and $R=R_{\text {test }}$ mandatory survival tests for the 


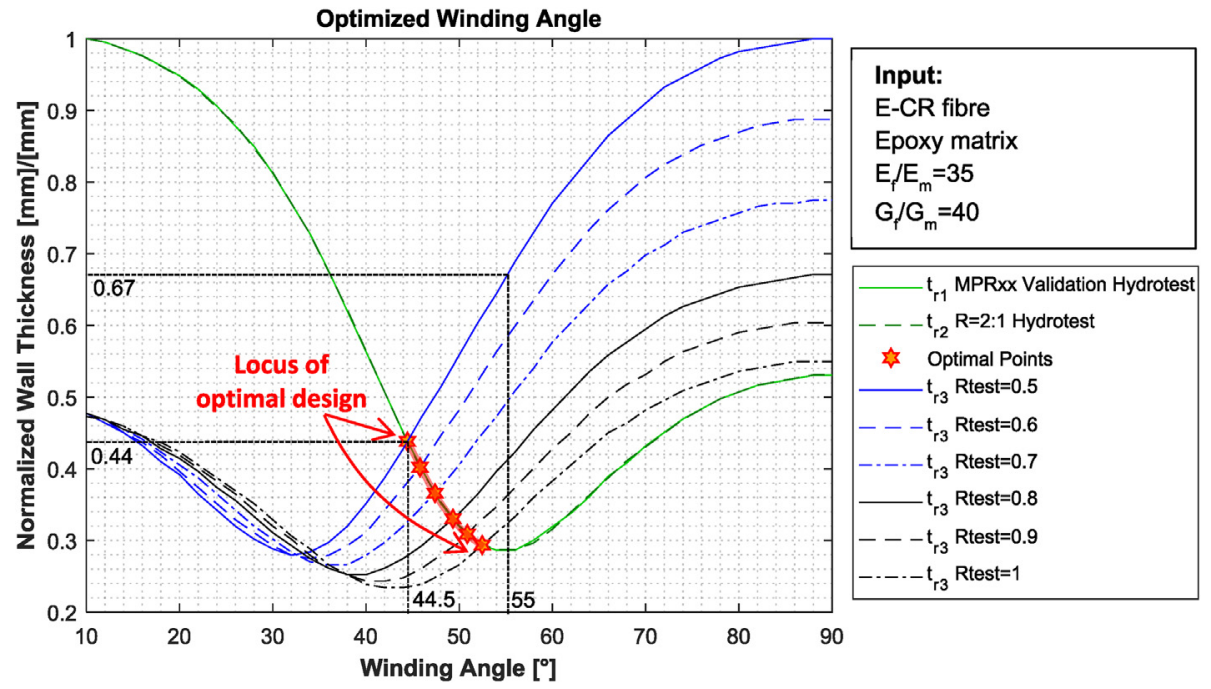

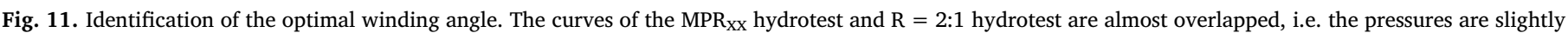
different.

validation of data points.

Indeed, the relative position of the three curves is independent on the $\mathrm{MPR}_{\mathrm{xx}}$ or on the diameter (that is the size) of the considered pipe, which are the two main inputs of the qualification process and of the design in accordance with the ISO standard.

The plot of Fig. 11 underlines the importance of the new design process proposed into the ISO 14692, and especially of the $R=R_{\text {test }}$ pressure test. This test reflects the importance of the axial stresses generated into the pipeline, as well as the necessity to customize the pipe based on an appropriate selection of the winding angle. Moreover, this plot is a sort of sensitivity analysis, that underlines the influence of the $R_{\text {test }}$ parameter, thus of the stress multi-axiality, on the thickness estimation. After selecting the required $\mathrm{R}_{\text {test }}$, the designer can use this plot to determine the optimal winding angle and the related wall thickness.

The implemented assessment procedure is a tool that can help the designers during the initial stages of a project, for instance in the manufacturer selection or for a feasibility study. Anyway, this should be a draft indication, and does not substitute the experimental tests, as explicitly indicated into the standard. If available, the results from the ASTM D2992 experimental testing can limit the study to the only two surfaces of the $R=2: 1$ hydrotest and the $R=R_{\text {test }}$ pressure test.

\section{Conclusions}

The paper presents an analytical study for the optimization of the manufacturing parameters of a plain pipe in GFR composite. The work follows three design steps.

The first step starts from the fibre and matrix properties and content, estimating lamina elastic properties and strengths by appropriate theoretical micro-mechanics models. It is shown that there is a region between $V_{f}=20-40 \%$ where the transverse strength $S_{2}$ of the lamina is very low, meaning that fibre content should be increased as much as possible, to improve $S_{2}$ and avoid weepage failure mode of the pipe.

Then, the second step estimates the mechanical properties of the laminate by means of the classical laminate theory. The simple inner pressure loading condition (hydrotest), combined with the different failure criteria, leads to the estimation of the minimum required wall thickness. The trends of this parameter is studied as a function of: 1) the volume fraction, evidencing a minimum at $V_{f}=45-60 \%$, and 2) the winding angle, evidencing a minimum at $\theta= \pm 55^{\circ}$. These two optimized parameters are well known in the industrial field and are included into the composite design indications of the main available standards.

Finally, the third step implements the procedure of the recent ISO 14692 standard, which includes not only hydrotests but also the combined presence of pressure and axial loads. The effect of these loads modifies the optimal design parameters. In the paper it is shown that the optimal winding angle is actually variable in the range $\pm 44.5^{\circ}<\theta< \pm 52.5^{\circ}$ based on the effective axial loads present into the pipe, estimated by the $\mathrm{R}_{\text {test }}$ parameter. Forcing the winding angle to $\pm 55^{\circ}$ will result in an increase in the required wall thickness up to $50 \%$. From these considerations, we can suggest a customization in the pipe production, based on the estimated axial loads in exercise.

The implemented procedure provides useful information for the design and assessment of a plain composite pipe, and it is a tool that can help the designers during the initial stages of a project, for instance in the manufacturer selection or for a feasibility study.

\section{Acknowledgements}

The authors want to thanks Eng. Andrea Ceresetti, former Master student at Politecnico, for his contribute in the development of the code during his Master thesis.

\section{References}

[1] Zaman A, Gutub SA, Wafa MA. A review on FRP composites applications and durability concerns in the construction sector. J Reinforc Plast Compos 2013;32(24):1966-88. http://dx.doi.org/10.1177/0731684413492868.

[2] Jin NJ, Hwang HG, Yeon JH. Structural analysis and optimum design of GRP pipes based on properties of materials. Construct Build Mater 2013;38(Supplement C):316-26. http://dx.doi.org/10.1016/j.conbuildmat.2012.07.115. 25th Anniversary Session for ACI 228-Building on the Past for the Future of NDT of Concrete.

[3] Oswald KJ. Thirty years of fiberglass pipe in oilfield application: a historical perspective. Mater Perform 1996;35(5):65-8.

[4] Pavlou DG. Composite materials in piping applications. Design, analysis and optimization of subsea and onshore pipelines from FRP materials. DEStech Publications, Inc.; 2013.

[5] Amani M, Rauf AA. An update on the use of fiberglass casing and tubing in oil and gas wells. Int J Petrol Petrochem Eng 2017;3(4):43-53. http://dx.doi.org/10. 20431/2454-7980.0304004.

[6] Yu K, Morozov EV, Ashraf MA, Shankar K. A review of the design and analysis of reinforced thermoplastic pipes for offshore applications. J Reinforc Plast Compos 2017;36(20):1514-30. http://dx.doi.org/10.1177/0731684417713666.

[7] ISO 14692. Standard: petroleum and natural gas industries - glass-reinforced plastics (GRP) piping. Part 1: vocabulary, symbols, applications and materials; Part 2: qualification and manufacture; Part 3: system design; Part 4: fabrication, installation and operation 2017.

[8] Webinar P. FRP Pipe failures \& lessons to be learned Dynaflow Research Group; 
2008. Technical report.

[9] Laney P. Use of composite pipe materials in the transportation of natural gas. Idaho International Engineering and Environmental Laboratory, Bechtel BWXT Idaho, LLC; 2002.

[10] Chan A, Munro M, Fahim A. Accuracy-speed relationships of a robotic filament winding cell. Robot Comput Integrated Manuf 1996;12(1):3-13. http://dx.doi.org/ 10.1016/0736-5845(95)00025-9. ISSN 0736-5845.

[11] Brent Strong A. Fundamentals of composites manufacturing. Materials, methods, and applications. second ed. Society of Manufacturing Engineers; 2008.

[12] API 15 HR. specification: high pressure fiberglass line pipe. fourth ed. 2016.

[13] Meijer G, Ellyin F. A failure envelope for $\pm 60^{\circ}$ filament wound glass fibre reinforced epoxy tubulars. Composites Part A 2008;39(3):555-64. http://dx.doi.org/ 10.1016/j.compositesa.2007.11.002. ISSN 1359-835X.

[14] Roylance DK. Netting analysis for filament wound pressure vessels Technical report Watertown, MA: Composites Division, Army Materials and Mechanics Research Center; 1976 AMMRC TN 76-3.

[15] EN ISO 14692. Standard: petroleum and natural gas industries - glass-reinforced plastics (GRP) piping. Part 1: vocabulary, symbols, applications and materials; Part 2: qualification and manufacture; Part 3: system design; Part 4: fabrication, installation and operation 2002

[16] MECH-Gcomp. URL https://gcomp-srv01.nuvem.ufrgs.br/en/.

[17] Kaw AK. Mechanics of composite materials. second ed. Taylor \& Francis Group, L.L.C.; 2006.

[18] Halpin JC, Kardos JL. The Halpin-Tsai equation: a review article. Polym Eng Sci 1976;16(5):344-52. http://dx.doi.org/10.1002/pen.760160512.

[19] Chamis CC. Simplified composite micromechanics equations for strength, fracture toughness and environmental effects. Cleveland, Ohio, USA: NASA, Lewis Research Center; 1984. Technical Memorandum N84-27832.

[20] Cohen D, Mantell SC, Zhao L. The effect of fiber volume fraction on filament wound composite pressure vessel strength. Composites Part B 2001;32(5):413-29. http://
dx.doi.org/10.1016/S1359-8368(01)00009-9.

[21] Nettles A. Basic mechanics of laminated composite plates vol. 1351. NASA Reference Publication; 1994.

[22] Puck A, Schürmann H. Failure analysis of FRP laminates by means of physically based phenomenological models. Compos Sci Technol 1998;58(7):1045-67. http:// dx.doi.org/10.1016/S0266-3538(96)00140-6.

[23] Jones MLC, Hull D. Microscopy of failure mechanisms in filament-wound pipe. J Mater Sci 1979;14(1):165-74.

[24] Arikan H. Failure analysis of $\left( \pm 55^{\circ}\right)_{3}$ filament wound composite pipes with an inclined surface crack under static internal pressure. Compos Struct 2010;92(1):182-7. http://dx.doi.org/10.1016/j.compstruct.2009.07.027.

[25] Mahdavi HR, Rahimi GH, Farrokhabadi A. Failure analysis of $\left( \pm 55^{\circ}\right)_{9}$ filamentwound gre pipes using acoustic emission technique. Eng Fail Anal 2016;62:178-87. http://dx.doi.org/10.1016/j.engfailanal.2015.12.004.

[26] Colombo C, Vergani L. Influence of delamination on fatigue properties of a fibreglass composite. Compos Struct 2014;107:325-33. http://dx.doi.org/10.1016/j. compstruct.2013.07.028.

[27] Ellul B, Camilleri D, Grech J, Muscat M. Filament wound composite pressure vessels and pipes subject to an internal pressure: an experimental and material characterization study. ASME J Pressure Vessel Technol 2016. http://dx.doi.org/10.1115/1. 4032506. 138-8(6): 060907-060907.

[28] Gentile G. Resistenza a pressione interna di tubi in composito ottenuti per Filament Winding Università di Napoli Federico II, Dipartimento di Ingegneria dei Materiali e della Produzione, Dottorato di ricerca in Tecnologie di Sistemi di Produzione (XX ciclo); 2008. PhD thesis.

[29] ASTM D2992. Standard practice for obtaining hydrostatic of pressure design basis for 'fiberglass' (Glass-Fiber-Reinforced thermosetting-resin) pipe and fittings. 2012

[30] ASTM D1598. Standard test method for time-to-failure of plastic pipe under constant internal pressure. 2015. 